\title{
Anti-Corrosion Application of Poly(indole-5- carboxylic Acid) Coating on Low Nickel Stainless Steel in Acidic Medium
}

\author{
P. KARTHIKEYAN and R. RAJAVEL*
}

Department of Chemistry, Periyar University, Salem - 636 011, Tamilnadu, India

drrajavelpu@gmail.com

Received 1 September 2016 / Accepted 10 October 2016

\begin{abstract}
Poly(indole-5-carboxylic acid) (PICA) has been synthesized by electrochemical polymerization technique from different concentration of poly(indole-5-carboxylic acid) using lithium per chloride as oxidation agent at different scan rate. The as-synthesized PICA was characterized using Fourier transform infrared spectroscopy (FT-IR) and Proton nuclear magnetic resonance spectroscopy $\left({ }^{1} \mathrm{H}-\mathrm{NMR}\right)$. Thermal analysis of the PICA was performed by Thermo gravimetric analysis (TGA). The corrosion protection performance of low nickel stainless steel (LN SS) specimens coated with $0.1 \mathrm{M}$ concentration of PICA was investigated in $0.5 \mathrm{M} \mathrm{H}_{2} \mathrm{SO}_{4}$ medium using potentiodynamic polarization and electrochemical impedance spectroscopic (EIS) methods. The morphological properties of the polymer were characterized by scanning electron microscopy (SEM). The as-synthesized PICA has been used in order to achieve adherent, as well as environmentally preferential good anti-corrosive coating. Electrochemical corrosion tests and surface analysis results evidently showed that PICA coating served as a stable mass matrix on LN SS against corrosion. It was also revealed that the coating of PICA at $0.1 \mathrm{~V}$ scan rate with $0.1 \mathrm{M}$ indole-5-carboxylic acid exhibited the best corrosion resistance among all concentrations.
\end{abstract}

Keywords: LNSS, Indole-5-carboxylic acid, Corrosion protection, Electrochemical study

\section{Introduction}

Stainless steel and it's alloys are one of the most useful metal for various application, such as in construction, pipe work, power plants in cooling water systems and in the oil and gas production industries ${ }^{1,2}$. Stainless steel (SS) is extensively used in many fields due to their exceptional corrosion resistance property. The largest part of stainless steel equipment failure are caused by chloride ions, particularly in cooling water systems the pitting and crevice corrosion are still the serious problems of stainless steel $^{3}$. Surface treatment procedures such as electro polishing, low temperature nitridization and passivation have been used to enhance the resistivity of the metals ${ }^{4-7}$. The increasing application of the 
stainless steel to improve efficient and environmentally complicated method, corrosion and either inhibitors or conducting polymer coating ${ }^{8-12}$. In recent times, conducting polymers have received considerable attention as corrosion protective coatings for oxidizable metals. It is now well-known that electrochemical polymerization is an effortless and most suitable method for corrosion protection ${ }^{13-16}$. The present work deals with the electro polymerization of PICA coating on LN SS in $0.5 \mathrm{M} \mathrm{H}_{2} \mathrm{SO}_{4}$ medium.

\section{Experimental}

Indole-5-carboxylic acid (Sigma-Aldrich), $\mathrm{LiClO}_{4}$ (Merck) and acetonitrile (Merck) were of AR grade and used without further purification. All aqueous solutions were prepared using deionized water.

\section{Preparation of substrate}

For our study, we have used LN SS samples were used as specimens for the corrosion studies. The following chemical composition of LN SS was used for the experiment with composition (wt \%) C-0.063, Si-0.35, Mn-7.05, P-0.054, S-0.01, Cr-16.03, Ni-4.16, N-0.1, $\mathrm{Cu}-1.24$, Fe-balance. The LN SS specimens were cut into an overall apparent size of $1 \times 1$ $\times 0.3 \mathrm{~cm}$ and embedded in epoxy resin with suitable electrical contact to have an exposed area of $1 \mathrm{~cm}^{2}$.

Prior to each experiment, the specimen was polished with different grade of $\mathrm{SiC}$ papers from 120 to 1200 grit. The final polishing was done with coarse 6 and $1 \mu \mathrm{m}$ diamond pastes in order to produce scratch free mirror finish surface and then degreased with acetone. Further, the specimens were cleaned using ultrasonication in acetone solution for 30 minutes, dried and used for further studies.

\section{Electrochemical synthesis of PICA}

The electrochemical deposition process was carried out in three electrode cell assembly. The working electrode was LN SS. The counter and reference electrode was platinum and saturated calomel electrode (SCE), respectively. Cyclic voltametric (CV) condition were maintained using an Electrochemical workstation (CHI760C, $\mathrm{CH}$ instrument USA) and at constant temperature $28 \pm 1^{\circ} \mathrm{C}$. PICA was electrodeposited on LN SS by cyclic voltametry $(\mathrm{CV})$ between $-0.6-2.1 \mathrm{~V}$ and scans rate $100 \mathrm{mV} \mathrm{s}^{-1}$ with at different concentrations of $0.01 \mathrm{M}$ 0.1 M 0.2 M. Further, the working electrode LN SS were remove from the electrolyte and washed with water finally dried at room temperature.

\section{Electrochemical studies}

The electrochemical studies of electrochemical spectroscopy, impedance and Tafel were carried out using the same setup by using $0.5 \mathrm{M} \mathrm{H}_{2} \mathrm{SO}_{4}$ as an electrolyte. The applied ac perturbation signal was about $100 \mathrm{mV}$ within the frequency range $100 \mathrm{kHz}$ to $1 \mathrm{kHz}$. All the electrochemical impedance measurements were carried out with respect to the open circuit potential.

\section{Characterization of polymers}

The structural characterization of FT-IR spectra of the polymer coating formed by electrochemical deposition were recorded in NICOLET 380 FT-IR instrument in the wave number range $400-4000 \mathrm{~cm}^{-1}$. The polymer sample were collected from the LN SS surface and pellets of them with spectroscopic $\mathrm{KBr}$. The proton NMR spectroscopy (Bruker DRX $400 \mathrm{MHz}$ ) was using DMSO as solvent with as-synthesized polymer to find the structure of 
the PICA polymer. Surface characterization of polymer coating was observed field emission scanning electron microscopy coupled with energy dispersive $\mathrm{x}$-ray analysis was carried out on a (UK) instrument. Thermo gravimetric analysis (TGA) was carried out in a TGA model Q50 V20.6 build 31 systems at a heating rate of $20^{\circ} \mathrm{C}$ per minute under a nitrogen atmosphere were carried out on PICA coated LN SS.

\section{Results and Discussion}

The FT-IR spectrum, Figure $1 \mathrm{~b}$ showed the absorption peak at $1685 \mathrm{~cm}^{-1} \mathrm{C}=\mathrm{O}$ for stretching mode and broad band at $3423 \mathrm{~cm}^{-1}$ for $-\mathrm{OH}$ and $\mathrm{N}-\mathrm{H}$ stretching mode. In addition the FT-IR spectrum of the polymer peak at $1086 \mathrm{~cm}^{-1}$ and $939 \mathrm{~cm}^{-1}$ are clearly observed for perchlorate peaks Figure 1b, wherein the peak at $1318,1387,1633$ and $822 \mathrm{~cm}^{-1}$ assigned to the $\mathrm{C}-\mathrm{N}, \mathrm{COO}^{-}, \mathrm{C}=\mathrm{C}$, and $\mathrm{C}-\mathrm{H}$ modes, respectively. Similarly, all the peaks are observed for the ICA monomer (Figure 1a). Thus the FT-IR spectra are confirmed the formation of PICA and the presence of $\mathrm{ICA}^{17}$.

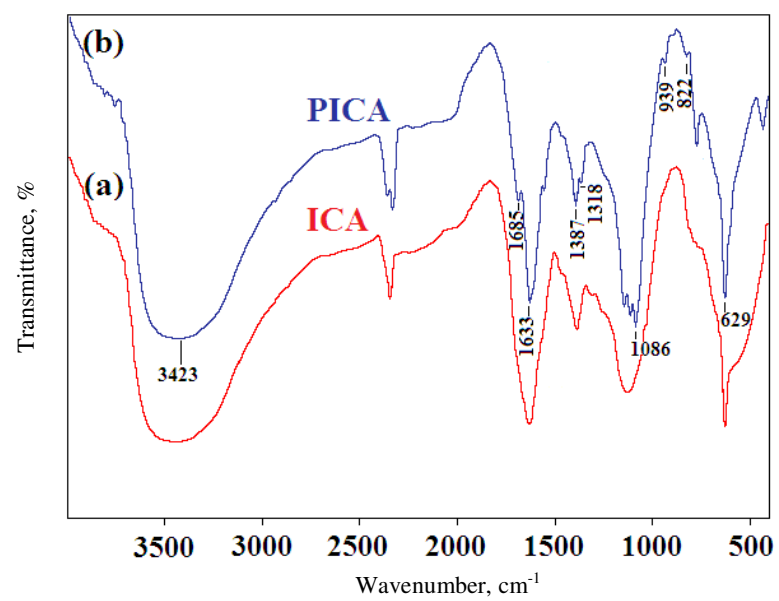

Figure 1. (a) The FT-IR spectrum of ICA monomer and (b) PICA coated LN SS at 0.1 M of ICA

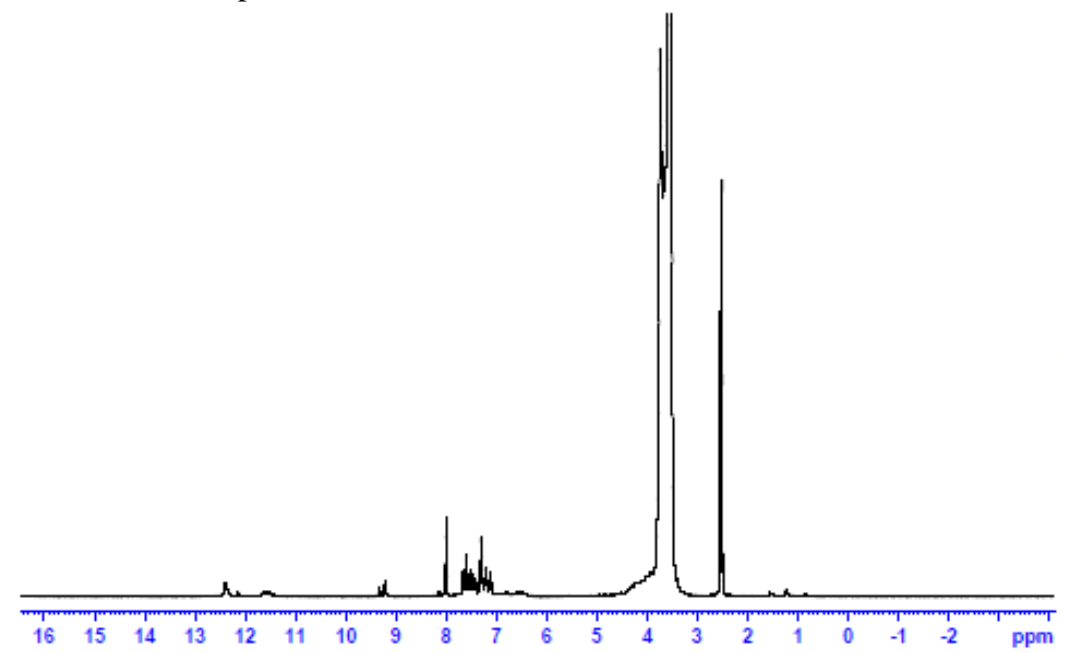

Figure 2. ${ }^{1} \mathrm{H}$ NMR spectrum of PICA coated LN SS at $0.1 \mathrm{M}$ of ICA 
${ }^{1} \mathrm{H}$ NMR studies explained the structure and formation of polymer at different mole ratio of PICA was carried (c.f. Figure 2). The two strongest peaks at $2.34 \mathrm{ppm}$ and $3.53 \mathrm{ppm}$ are certified to proton of DMSO and water in DMSO. The signal present at $11.42-11.53 \mathrm{ppm}$ corresponds to N-H proton and $12.33 \mathrm{ppm}$ peak at $-\mathrm{COOH}$ proton of the polymer. The peak at a separate signal at $7.8-8.1$ and $9.44 \mathrm{ppm}$ which is corresponds to the aromatic rings of ICA monomer ${ }^{17}$.

The FESEM technique is good tool to evaluate the surface morphology of the PICA polymer coating on LN SS. The morphology of the PICA polymer deposited on LN SS is presented in the Figure $3 \mathrm{a}$ and showed the small granules like structure uniformly covered on the surface of LN SS specimen. Figure $3 b$ shows the EDAX spectrum of the PICA polymer coated sample which is indicate the presence of $\mathrm{C}, \mathrm{N}, \mathrm{O}$ and $\mathrm{Cl}$ there by confirming existence of the PICA polymer coating on LN SS sample?.

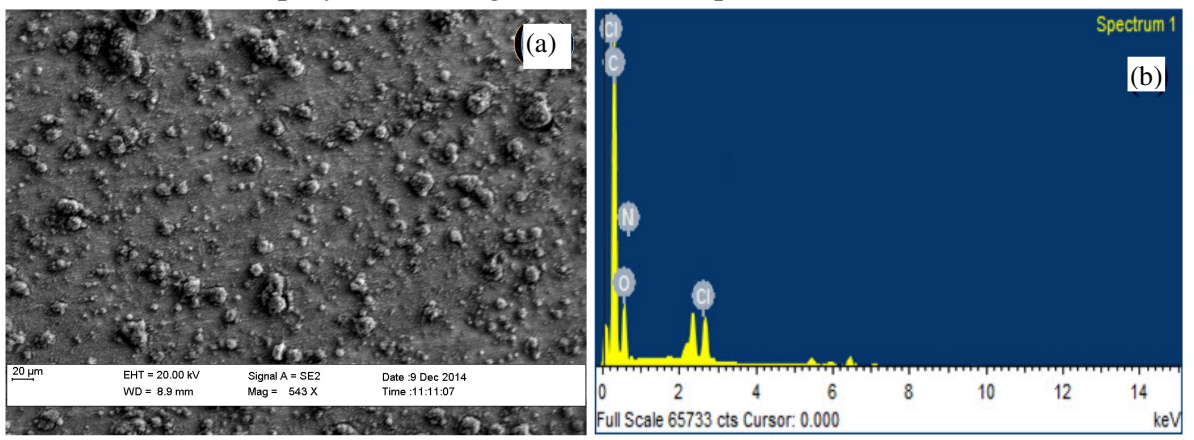

Figure 3. (a) The FESEM morphology of PICA coated LN SS at $0.1 \mathrm{M}$ of ICA and EDAX spectrum of PICA coated LN SS at $0.1 \mathrm{M}$ of ICA

Figure 4a shows the potentiodynamic polarization curves of uncoated and PICA coated LN SS in $0.5 \mathrm{M} \mathrm{H}_{2} \mathrm{SO}_{4}$ medium and their corresponding potentiodynamic polarization parameters such as corrosion potential $\left(\mathrm{E}_{\text {corr }}\right)$ and corrosion current density $\left(\mathrm{I}_{\text {corr }}\right)$ are given in Table 1 . The curves were recorded with a potential range between $-1000 \mathrm{mv}$ and $+1000 \mathrm{mv}$. Figure $4 \mathrm{~b}$ shows the Nyquist plots of the uncoated and PICA coated LN SS in $0.5 \mathrm{M} \mathrm{H}_{2} \mathrm{SO}_{4}$ medium. The $R_{p}$ value obtained for the uncoated specimen is $147 \Omega \mathrm{cm}^{2}$. The higher $R_{p}$ value obtained for the PICA coated LN SS demonstrated that the matrix like polymer layer covers the metal surface completely and protects against the corrosive ions significantly (Table 1).

The thermal stability of PICA tested at temperature range of $100-1000{ }^{\circ} \mathrm{C}$ with heating rate of $20 \mathrm{~K} \mathrm{~min}^{-1}$. From Figure 5 considerable degradation of PICA is observed at 105, 260, 490 and $830{ }^{\circ} \mathrm{C}$. The weight losses are observed at $105^{\circ} \mathrm{C}$ and $260{ }^{\circ} \mathrm{C}$ due to evaporation of the water and $\mathrm{CO}_{2}$ respectively. The decomposition at $490{ }^{\circ} \mathrm{C}$ indicates that the mass loss was attributed to the $-\mathrm{COOH}$ group into $\mathrm{CO}_{2}$. The mass loss at $830^{\circ} \mathrm{C}$ was obtained due to the residue of the constant weight.

Table 1. Potentiodynamic polarization and impedance parameter of uncoated and PICA coated sample in $0.5 \mathrm{M} \mathrm{H}_{2} \mathrm{SO}_{4}$

\begin{tabular}{ccccc}
\hline S.No. & Sample & $\mathrm{E}_{\text {corr }}(\mathrm{V} / \mathrm{SCE})$ & $\mathrm{I}_{\text {corr }}\left(\mathrm{mA} / \mathrm{cm}^{2}\right)$ & $\mathrm{R}_{\mathrm{p}}\left(\Omega \mathrm{cm}^{2}\right)$ \\
\hline 1 & uncoated & -449 & 0.72 & 147 \\
2 & $0.01 \mathrm{M}$ & -422 & 0.28 & 553 \\
3 & $0.1 \mathrm{M}$ & -343 & 0.08 & 1138 \\
4 & $0.2 \mathrm{M}$ & -373 & 0.17 & 772 \\
\hline
\end{tabular}



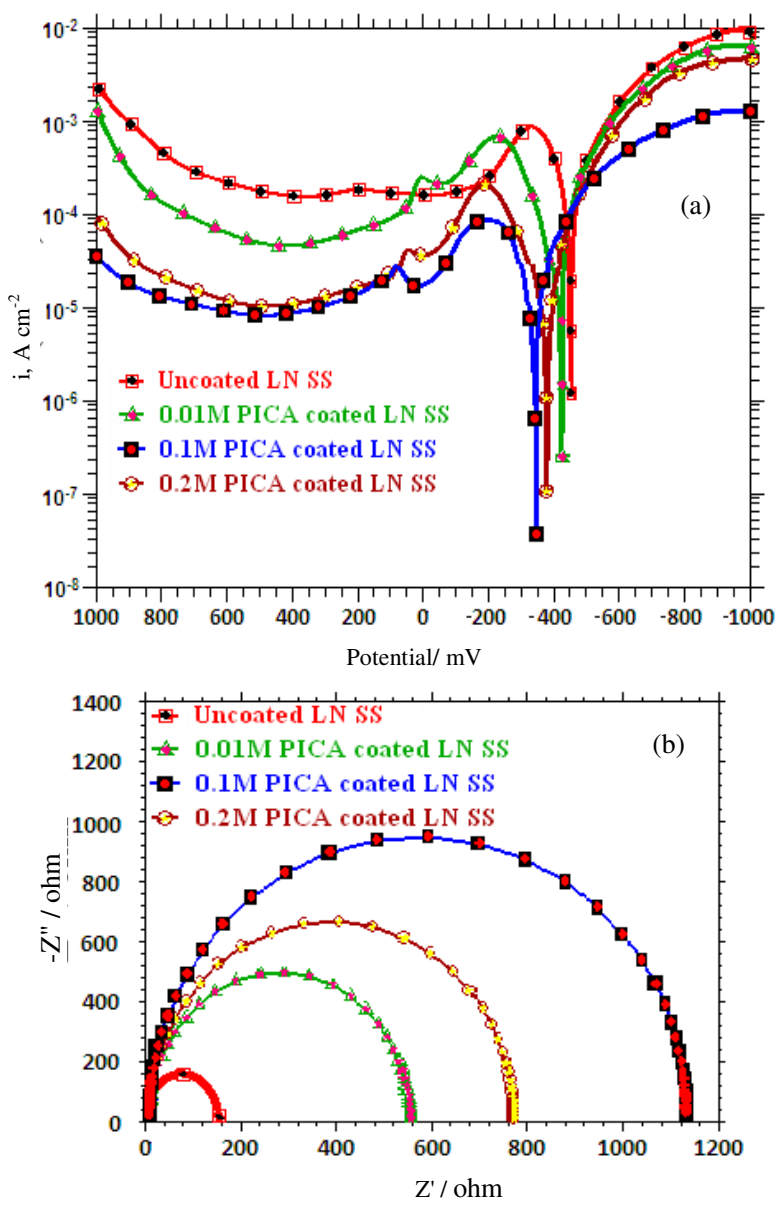

Figure 4. (a) Potentiodynamic polarization curve of uncoated and PICA coated sample in $0.5 \mathrm{M} \mathrm{H}_{2} \mathrm{SO}_{4}$ (b) Potentiodynamic impedance curve of uncoated and PICA coated sample in $0.5 \mathrm{M} \mathrm{H}_{2} \mathrm{SO}_{4}$

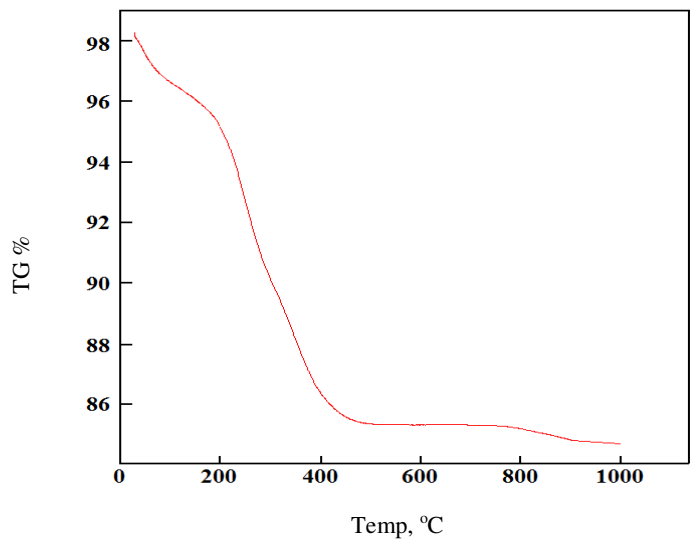

Figure 5. Thermo gravimetric curve for degradation of PICA 
The structure of the polymer PICA coating was confirmed by FT-IR and NMR spectra and FESEM show the surface morphology of the polymer coating on LN SS which fully covered and the entire surface of the coating and EDAX spectrum supports the presence of elements in the coated material. The potentiodynamic polarization study confirms the polarization curve more towards the anodic direction and without doubt, the enhanced corrosion protection is exhibited by PICA coating on LN SS. Moreover the TGA analysis showed the better thermal stability for the PICA polymer than that of monomer.

\section{Conclusion}

Electropolymerized coatings of PICA on LN SS were successfully carried out by cyclic volammetric technique. The PICA coated on LN SS was characterized by the FT-IR, NMR, FE-SEM, EDAX, potentiodynamic polarization and electrochemical impedance studies. The results are revealed that the $0.1 \mathrm{M}$ concentration of PICA coated LN SS acts as a better protective layer than that obtained at other concentrations on LN SS against corrosion protection in $0.5 \mathrm{M} \mathrm{H}_{2} \mathrm{SO}_{4}$ medium.

\section{Acknowledgement}

P. Karthikeyan acknowledges the support received from Periyar University in the form of University Research Fellowship (URF).

\section{References}

1. Baddoo N R, J Constructional Steel Res., 2008, 64(11), 1199-1206; DOI:10.1016/j.jcsr.2008.07.011

2. Lox E S J and Engler B H, in Handbook of Heterogeneous Catalysis, Ed., by Ertl G, Kn ozinger H, Weitkamp, 1997 J. Wiley-VCH 1559.

3. Osaka T, Ogano S, Naoi K and Oyama N J, Electrochem Soc., 1989, 136(2), 306-309; http://dx.doi.org/10.1149/1.2096626

4. Kocijan A, Donik C and Jenko M, Corros Sci., 2007, 49, 2083-2098; DOI:10.1016/j.corsci.2006.11.001

5. Prabakaran K and Rajeswari S, J Appl Electrochem., 2009, 39(6), 887-897; DOI:10.1007/s10800-008-9738-5

6. Nazeen F, Galvin P, Arrigandw M, Thompson M, Benvenuto P and Herzog G, J Solid State Electrochem., 2012, 16(3), 1389-1397; DOI:10.1007/s10008-011-1539-9

7. Flis J, Wydorska M K, kabulska I F, J Solid State Electro Chem., 2006, 10, 689-695; DOI:10.1007/s10008-006-0112-4

8. Bereket G, Hur E and Sahin Y, Appl Surf Sci., 2005, 252, 1233-1244; DOI:10.1016/j.apsusc.2005.02.087

9. Çakmakcı I, Duran B, Duran M and Bereket G, Corros Sci., 2013, 69 252-261; DOI:10.1016/j.corsci.2012.12.011

10. Kilmartin P A, Trier L and Wright G A, Syn Metals, 2002, 131(1-3), 99-109; DOI:10.1016/S0379-6779(02)00178-9

11. Zeybek B, Pekmez N O and Kilıc E, Electrochim Acta, 2011, 56, 9277-9286; DOI:10.1016/j.electacta.2011.08.003

12. Siva T, Kamaraj K and Sathiyanarayanan S, Prog Org Coat., 2014, 77(11), 18071815; DOI:10.1016/j.porgcoat.2014.06.003

13. Sathiyanarayanan S, Dhawan S K, Trivedi D C and Balakrishnan K, Corros Sci., 1992, 33, 1831-1841; DOI:10.1016/0010-938X(92)90187-8

14. Beck F, Mechaelis R, Schloten F and Zinger B, Electrochim Acta, 1994, 39(2), 229234; DOI:10.1016/0013-4686(94)80058-8 
15. Cascalheria A C, Aeiyach S, Lacaze P C and Abrantes L M, Electrochim Acta, 2003, 48, 2523-2529; DOI:10.1016/S0013-4686(03)00295-0

16. Tuken T, Yazici B and Erbil M, Mater Des., 2007, 28, 208-216; DOI:10.1016/j.matdes.2005.04.006

17. Billaud D, Humbert B, Thevenot L, Thomas P and Talbi H, Spectrochim. Acta, 2003, 59(1), 163-168; DOI:10.1016/S1386-1425(02)00150-6

18. Nie G, Cai T, Zhang S, Bao Q and Xu J, Electrochim Acta, 2007, 52(24), 7097-7106; DOI:10.1016/j.electacta.2007.05.042 